\title{
Soldabilidade de Aços Resistentes à Abrasão da Classe de 450 HB de Dureza
}

\author{
(Weldability of Abrasion-Resistant Steels of $450 \mathrm{HB}$ Hardness)
}

\author{
Gabriel Corrêa Guimarães ${ }^{1}$, Ramsés Ferreira da Silva ${ }^{1}$, Luiz Carlos da Silva ${ }^{1}$ \\ ${ }^{1}$ Usiminas, Centro de Tecnologia Usiminas - Unidade Ipatinga, Ipatinga, Minas Gerais, Brasil.gabriel.guimaraes@usiminas.com, \\ ramses.silva@usiminas.com, luiz.silva@usiminas.com
}

\begin{abstract}
Resumo
Os aços resistentes à abrasão da classe de $450 \mathrm{HB}$ de dureza combinam a adição de carbono e de elementos de liga, visando à obtenção de uma microestrutura completamente martensítica e com elevada dureza ao longo de toda espessura da chapa. Porém, em virtude desta combinação, geralmente expressa pelo carbono equivalente, estes aços apresentam difícil soldabilidade. O objetivo deste trabalho foi avaliar a soldabilidade de dois aços resistentes à abrasão da classe de $450 \mathrm{HB}$ de dureza, aos quais se distinguem o carbono equivalente e a espessura. Realizou-se ensaio Tekken para avaliação da susceptibilidade ao trincamento a frio induzido por hidrogênio e para determinação da temperatura de préaquecimento para soldagem. Além disso, foram confeccionadas juntas soldadas utilizando-se o processo MIG/MAG automático com diferentes aportes térmicos. As juntas soldadas foram caracterizadas mediante análise metalográfica e ensaios mecânicos. Verificou-se que nenhum dos aços necessitou de préaquecimento. Observou-se que a junta soldada do aço de menor carbono equivalente apresentou melhores resultados de dobramento, principalmente, quando utilizada a maior energia de soldagem. Este aço também apresentou os maiores valores de energia absorvida por impacto Charpy-V.
\end{abstract}

Palavras-chave: Soldabilidade. Aço resistente à abrasão. Carbono equivalente. MIG/MAG.

Abstract: Abrasion-resistant steels of $450 \mathrm{HB}$ hardness combine carbon and alloying elements addition aiming a completely martensitic microstructure and high hardness by all thickness of the plate. But due this combination, generally represented by carbon equivalent, these steels present a difficult weldability. The aim of this work was evaluate the weldability of two abrasion-resistant steels of 450 HB hardness, both with different carbon equivalent and thickness. It was conducted Tekken test to evaluate the susceptibility to cold cracking induced by hydrogen and to determinate preheating temperature for welding. Besides that, welded joints using automatic MIG/MAG welding process with different heat inputs were manufactured. The welded joints were characterized by metallographic analyses and by mechanical tests. It was verified that both steels do not need preheating temperature. It was noted that the welded joints from steel with smaller carbon equivalent presented better results in the bending test, principally when used the higher heat input. This steel still presented bigger absorbed energy from the CharpyV impact test.

Key-words: Weldability. Abrasion-resistant steels. Carbon equivalent. MIG/MAG.

\section{Introdução}

Aços resistentes à abrasão da classe de $450 \mathrm{HB}$ de dureza são aços processados por tratamento térmico de têmpera e que apresentam microestrutura martensítica de elevada dureza ao longo de toda espessura da chapa, devido à combinação entre o carbono e os elementos de liga adicionados a estes aços. Esta combinação é geralmente expressa pelo carbono equivalente, que tem sido muito utilizado para estimar a soldabilidade dos aços [1].

Atualmente, diversas fórmulas [1,2] podem ser utilizadas para se calcular o carbono equivalente de um aço, sendo que algumas são mais representativas que outras, dependendo dos

(Recebido em 07/06/2011; Texto final em 10/12/2011).

Artigo originalmente publicado no CONSOLDA 2010 teores dos elementos químicos dos aços e de suas aplicações. Dentre estas fórmulas, a mais comumente utilizada é a proposta pelo IIW (International Institute of Welding), mostrada na Equação 1:

$C E=C+\frac{M n}{6}+\frac{C r+M o+V}{5}+\frac{N i+C u}{15}$

Quanto maior o carbono equivalente de um aço, maior sua susceptibilidade ao trincamento a frio induzido por hidrogênio, logo, maior sua dificuldade em proporcionar juntas soldadas de boa qualidade [1]. Porém, apesar de ser uma maneira rápida e fácil de avaliar a soldabilidade de um aço, o carbono equivalente não é suficiente para prevê-la. Fatores como espessura da chapa e energia de soldagem também devem ser levados em consideração $[1,3]$.

Buscando a melhoria de desempenho dos aços quanto à soldabilidade, novos projetos de liga têm sido desenvolvidos visando à redução do carbono equivalente, porém, sem 
Tabela 1. Composição química e sua especificação para os aços avaliados (A e B), assim como o CE e a espessura das chapas.

\begin{tabular}{|c|c|c|c|c|c|c|c|}
\hline \multirow{2}{*}{ Aço } & \multicolumn{5}{|c|}{ Elementos químicos (em \% peso) } & \multirow{2}{*}{ CE } & \multirow{2}{*}{$\begin{array}{c}\text { Espessura } \\
(\mathrm{mm})\end{array}$} \\
\cline { 2 - 8 } & $\mathrm{C}$ & $\mathrm{Mn}$ & $\mathrm{Cr}$ & $\mathrm{Ni}$ & $\mathrm{Cu}$ & & 9,5 \\
\hline $\mathrm{A}$ & 0,25 & 1,29 & 0,27 & 0,019 & 0,017 & 0,52 & - \\
\hline Especificação & $\leq 0,27$ & $\leq 1,50$ & $\leq 0,80$ & $\mathrm{NE}$ & $\mathrm{NE}$ & - & 8,0 \\
\hline B & 0,20 & 1,20 & 0,02 & 0,052 & 0,009 & 0,41 & - \\
\hline Especificação & $\leq 0,22$ & $\leq 1,50$ & $\leq 0,80$ & $\mathrm{NE}$ & $\mathrm{NE}$ & - & - \\
\hline
\end{tabular}

Nota: ${ }^{(a)} N E=$ não especificado
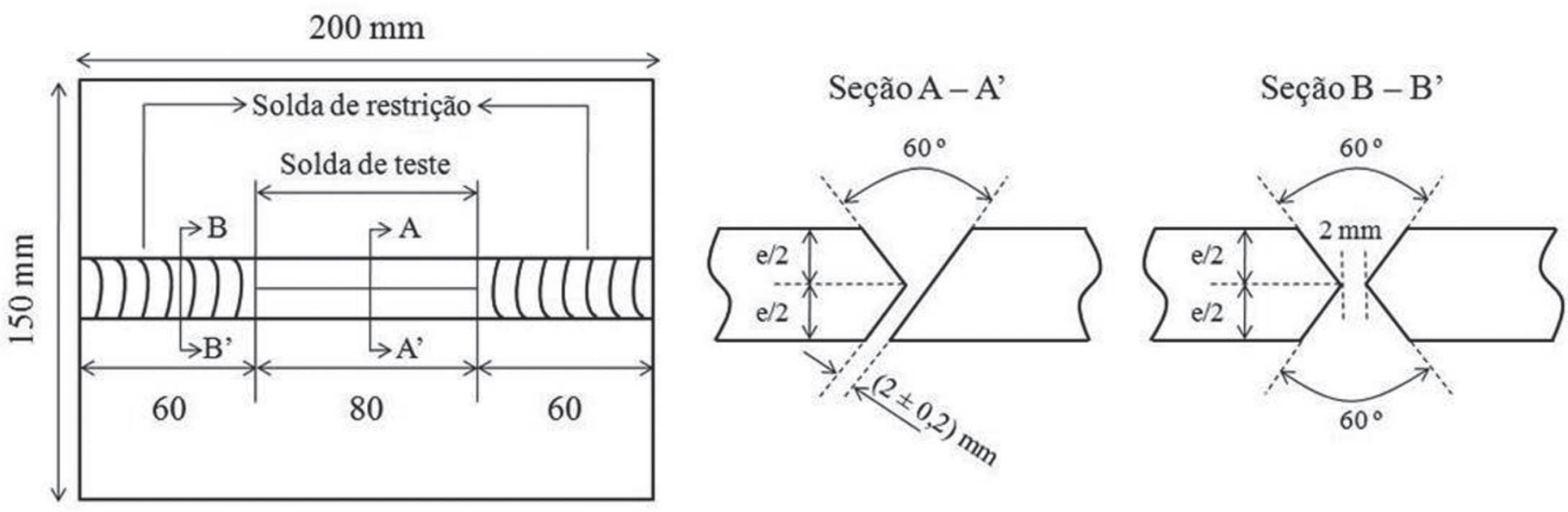

Figura 1. Ilustração do corpo de prova utilizado na realização do ensaio Tekken.

alteração das propriedades mecânicas dos aços. Sendo assim, este trabalho teve como objetivo avaliar a soldabilidade de dois aços resistentes à abrasão da classe de $450 \mathrm{HB}$ de dureza, com espessuras e CE distintos. As juntas soldadas foram obtidas utilizando-se o processo de soldagem MIG/MAG automático, sendo que, para cada aço, empregaram-se dois aportes térmicos diferentes.

\section{Procedimento Experimental}

\subsection{Materiais}

Foi avaliada a soldabilidade de dois aços cujas composições químicas e especificações encontram-se na Tabela 1. Nesta tabela ainda são apresentados o CE destes aços, Equação 1, e a espessura das chapas avaliadas.

\subsection{Ensaio Tekken}

Para avaliação da susceptibilidade ao trincamento a frio induzido por hidrogênio e determinação da temperatura de pré-aquecimento, realizou-se ensaio Tekken conforme a norma JIS Z 3158[4]. Na Figura 1 temse a ilustração do corpo de prova utilizado no ensaio. Dentre os ensaios de auto-restrição, o Tekken, é considerado um dos mais severos, em função do elevado grau de restrição imposto à solda (solda de restrição) e ao acentuado efeito do entalhe (ver seção A - A' na Figura 1)[3].

Os corpos de prova foram preparados conforme ilustrado na Figura 1, onde $e$ é a espessura da chapa. Os corpos de prova foram avaliados na temperatura ambiente. $\mathrm{O}$ processo de soldagem utilizado foi o MIG/MAG automático com consumível da classe AWS ER 70S-6 (490 MPa de limite de resistência). O aporte de calor empregado foi de $1,6 \mathrm{~kJ} / \mathrm{mm}$, com uma vazão de mistura gasosa ( $80 \%$ argônio e $20 \% \mathrm{CO}_{2}$ ) de $12 \mathrm{~L} / \mathrm{min}$.

Decorridas 12 horas da realização da solda de teste, verteuse solução aquosa de ácido clorídrico a $2 \%$ do lado da raiz do cordão de solda, a fim de promover a oxidação de possíveis trincas existentes, tanto na raiz quanto na seção do cordão. Por fim, após 48 horas da realização da solda de teste, retirou-se a solda de restrição através de corte na serra e encaminhou-se o corpo de prova para análise da ocorrência de trincas.

A medição do comprimento das trincas na face, na seção e na raiz do cordão de solda foi realizada de acordo a norma JIS Z 3158[4]. Foram avaliados 2 corpos de prova por aço.

\subsection{Confecção e Caracterização das Juntas Soldadas}

As juntas soldadas dos aços A e B foram confeccionadas utilizando-se aportes de calor de 1,0 e $1,6 \mathrm{~kJ} / \mathrm{mm}$. O processo e o consumível de soldagem utilizados foram os mesmos emprega- 
dos na realização do ensaio Tekken, assim como a vazão e a proporção da mistura gasosa. Na Figura 2 e na Tabela 2 apresentamse, respectivamente, a geometria do chanfro e os parâmetros de soldagem empregados.

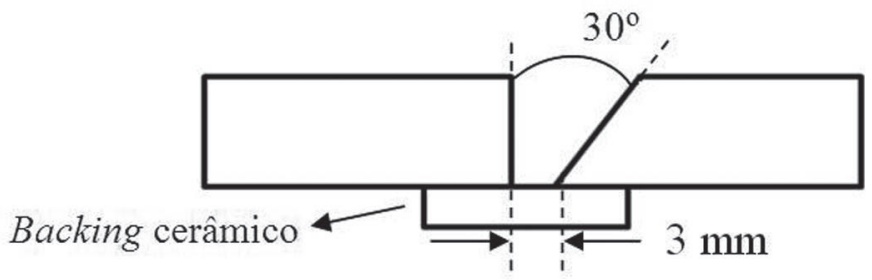

Figura 2. Ilustração da geometria do chanfro empregado na confecção das juntas soldadas dos aços A e B.

Tabela 2. Parâmetros de soldagem utilizados na confecção das juntas soldadas dos aços A e B.

\begin{tabular}{|l|c|c|}
\hline Energia de soldagem $(\mathrm{kJ} / \mathrm{mm})$ & 1,6 (alto) & 1,0 (baixo) \\
\hline Corrente $(\mathrm{A})$ & 260 & 200 \\
\hline Tensão $(\mathrm{V})$ & 26 & 24 \\
\hline Velocidade $(\mathrm{mm} / \mathrm{min})$ & 250 & 290 \\
\hline $\mathrm{N}^{\circ}$ de passes & 1 & 2 \\
\hline
\end{tabular}

Para caracterização das juntas soldadas, realizou-se análise metalográfica após ataque com reagente químico nital $4 \%$ em seções transversais à junta e no plano da espessura das chapas, com auxílio de microscópio ótico. Também foi realizado ensaio de dureza Vickers com carga de 1 kgf e distância entre impressões de $0,5 \mathrm{~mm}$.

Os corpos de prova para o ensaio de dobramento foram confeccionados segundo o código ASME, seção IX [5], e ensaiados com base na norma ASTM A370 [6]. A condição de dobramento utilizada foi a de $3 \mathrm{E} 90^{\circ}(\mathrm{E}=$ espessura da chapa), que é a mesma especificada para o metal base dos aços A e B. Foram realizados ensaios de dobramento tanto de face quanto de raiz. Os corpos de prova não reprovados a $90^{\circ}$ foram dobrados até $180^{\circ}$. Foram ensaiados 3 corpos de prova por condição de dobramento.

Os ensaios de impacto nas juntas soldadas foram realizados em corpos de prova Charpy-V do tipo subsize, com dimensões de $5 \times 10$ x $55 \mathrm{~mm}$, retirados no centro da espessura e confeccionados de acordo com a norma ASTM A370 [6]. Os entalhes foram posicionados na linha de fusão (LF) e em posições distanciadas a $2 \mathrm{~mm}$ e a $5 \mathrm{~mm}$ desta linha, no lado correspondente ao ângulo reto do chanfro. Foram ensaiados 3 corpos de prova por posição de entalhe para cada junta soldada. A temperatura empregada no ensaio foi de $-40^{\circ} \mathrm{C}$.

\section{Resultados e Discussão}

\subsection{Ensaio Tekken}

Observou-se que não houve trincamento a frio para ambos os aços após realização de ensaio Tekken à temperatura ambiente.
Desta forma, concluiu-se que nenhum dos aços necessita de préaquecimento para soldagem, possivelmente, devido às baixas espessuras das chapas. Sabe-se que quanto menores o CE e a espessura de um aço, menor sua susceptibilidade ao trincamento a frio induzido por hidrogênio [3]. $\mathrm{O}$ fato de o aço A não apresentar trincamento a frio, mesmo possuindo CE superior ao do aço B, sugere que a sua baixa espessura tenha contribuído para isto.

\subsection{Análises Metalográficas}

Nas Figuras 3 e 4 têm-se o aspecto macrográfico e o perfil de dureza das juntas soldadas dos aços A e B com energia de soldagem de $1,6 \mathrm{~kJ} / \mathrm{mm}$, respectivamente. De maneira geral, percebe-se que, em ambos os aços, não há variação significativa de dureza entre a zona termicamente afetada (ZTA) na face, no centro e na raiz. Todavia, nota-se que o perfil de dureza do aço A é bem distinto do apresentado pelo aço B, Figuras 3 (b) e 4 (b), respectivamente. Após queda a partir do metal base (MB), a dureza na ZTA do aço A elevase, tornando a diminuir até a dureza da região do metal de solda (MS). Já para o aço B, a dureza na ZTA diminui em relação ao metal base e eleva-se até o valor de dureza do metal de solda.

As microestruturas relativas a três regiões distintas daZTA dos aços A e B são apresentadas nas Figuras 5 e 6, respectivamente. Estas regiões estão indicadas como I, II e III nas Figuras 3 e 4. Comparando-se as microestruturas dos aços A e B nestas regiões, observa-se que elas são semelhantes, principalmente na região I, que apresenta martensita nos seus primeiros estágios de decomposição como constituinte. Nas regiões II e III, o aço A apresenta menor quantidade de ferrita que o aço B, logo, maior quantidade de constituintes de segunda fase, especialmente, bainita e martensita.

A explicação para a diferença observada no comportamento da dureza da ZTA entre os aços A e B pode estar relacionada ao maior $\mathrm{CE}$ do aço $\mathrm{A}$ e, também, à sua maior espessura. Quanto maior o CE de um aço maior sua propensão à formação de microestruturas de maior dureza na ZTA [7]. Além disso, o aço A possui espessura em torno de $20 \%$ maior que o aço B, ou seja, uma maior área para dissipação do calor gerado durante a soldagem. Isto contribui para o mais rápido resfriamento da ZTA, favorecendo ainda mais a formação de microestruturas de maiores durezas, como de fato observado nas Figuras 5 e 6.

Nas Figuras 7 e 8 têm-se o aspecto macrográfico e o perfil de dureza das juntas soldadas dos aços A e B com energia de soldagem de $1,0 \mathrm{~kJ} / \mathrm{mm}$, respectivamente. Nota-se que, em ambos os aços, na região indicada pelo retângulo tracejado, existem diferenças de dureza entre a ZTA da face, do centro e da raiz, ao contrário do que foi observado nas juntas soldadas com energia de soldagem de $1,6 \mathrm{~kJ} / \mathrm{mm}$. 


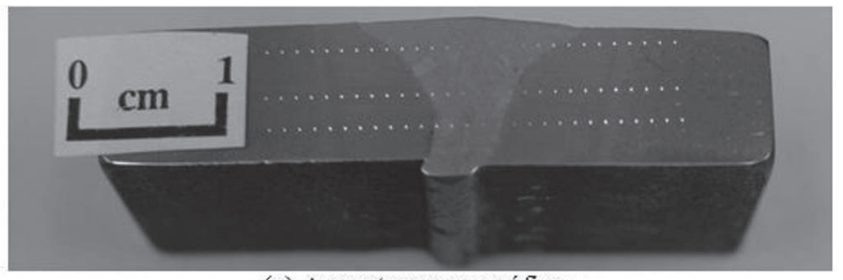

(a) Aspecto macrográfico.

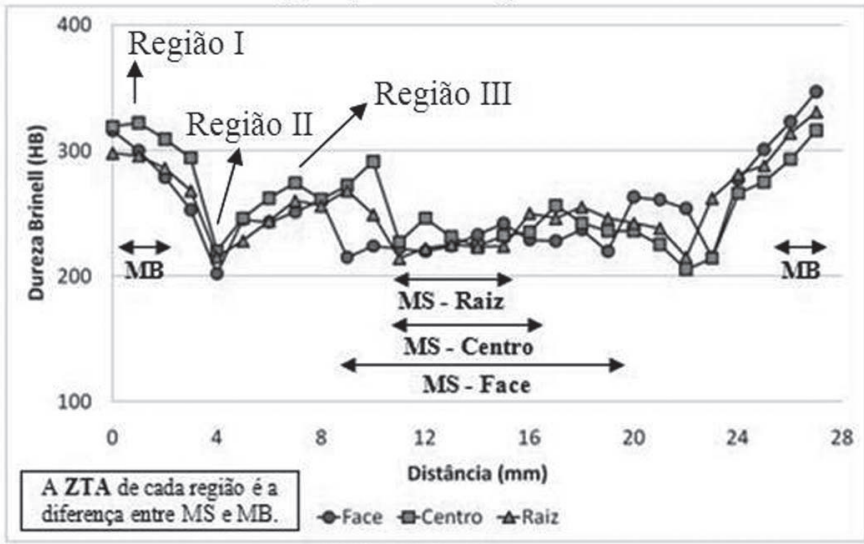

(b) Perfil de dureza.

Figura 3. Aspecto macrográfico e perfil de dureza Vickers da junta soldada do aço A com energia de soldagem de 1,6 kJ/mm.

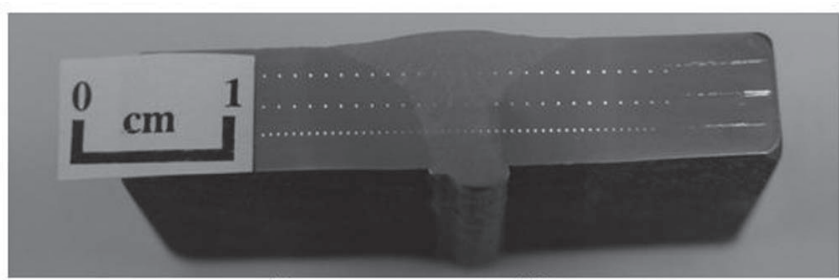

(a) Aspecto macrográfico.

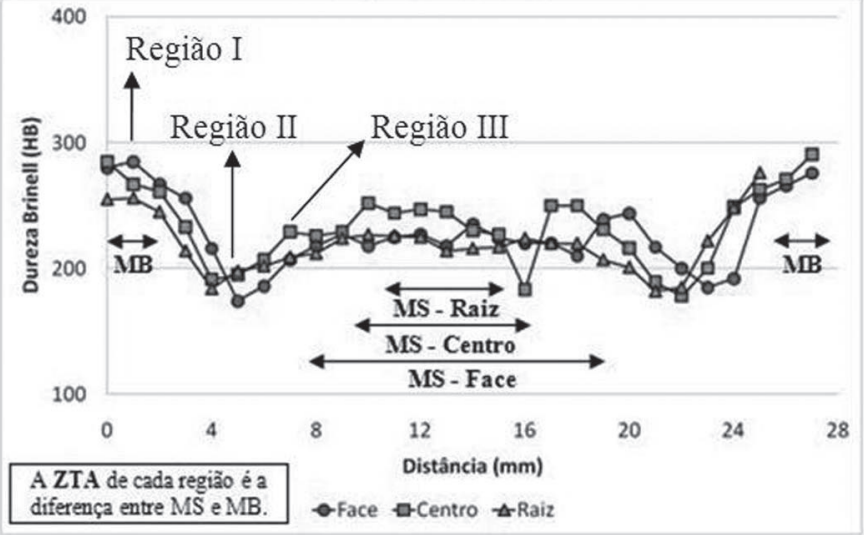

(b) Perfil de dureza.

Figura 4. Aspecto macrográfico e perfil de dureza Vickers da junta soldada do aço B com energia de soldagem de $1,6 \mathrm{~kJ} / \mathrm{mm}$.

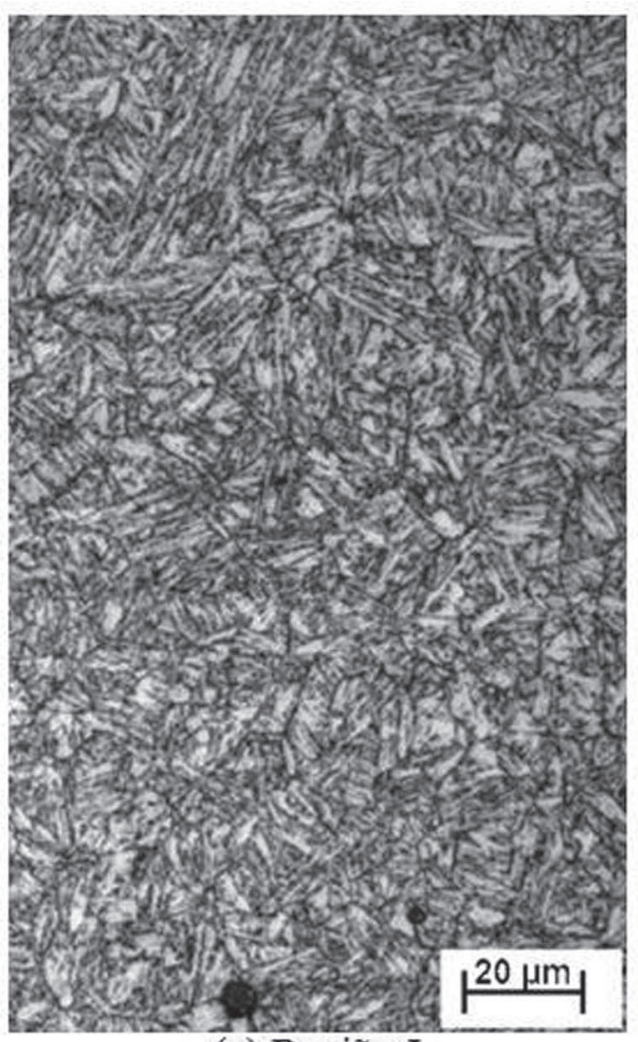

(a) Região I

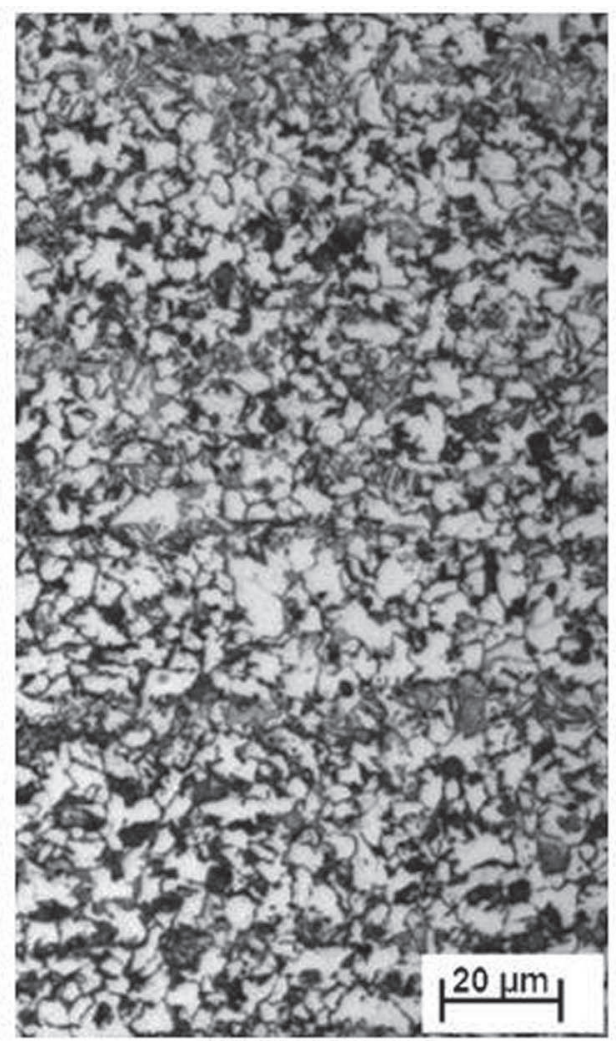

(b) Região II

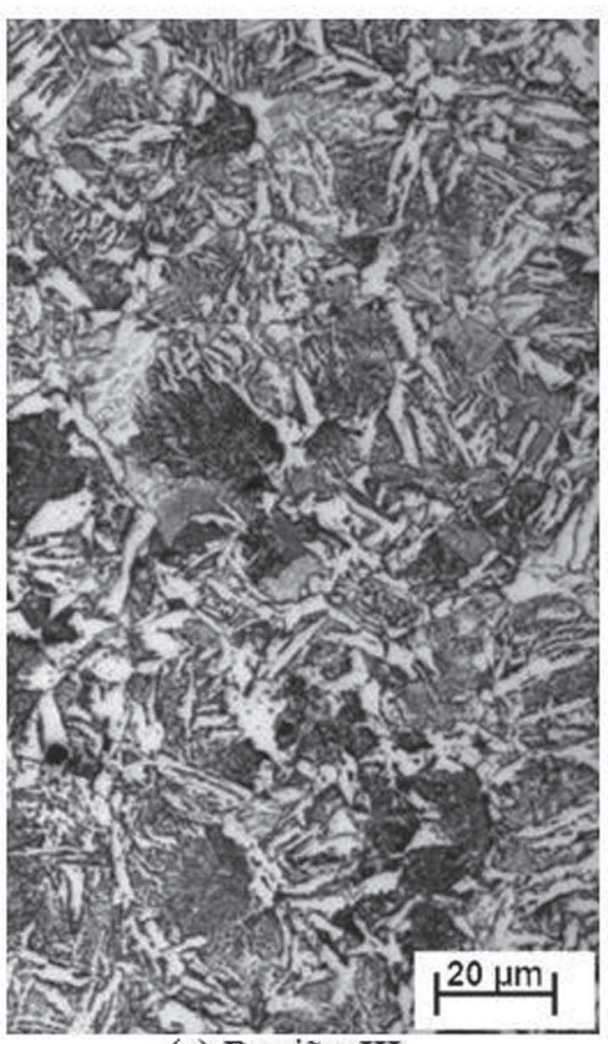

(c) Região III

Figura 5. Microestruturas das regiões I, II e III da ZTA do aço A, conforme indicado na Figura 3. Análise via microscopia ótica. Energia de soldagem: 1,6 kJ/mm. Aumento original: 500X. Ataque: nital 4\%. 


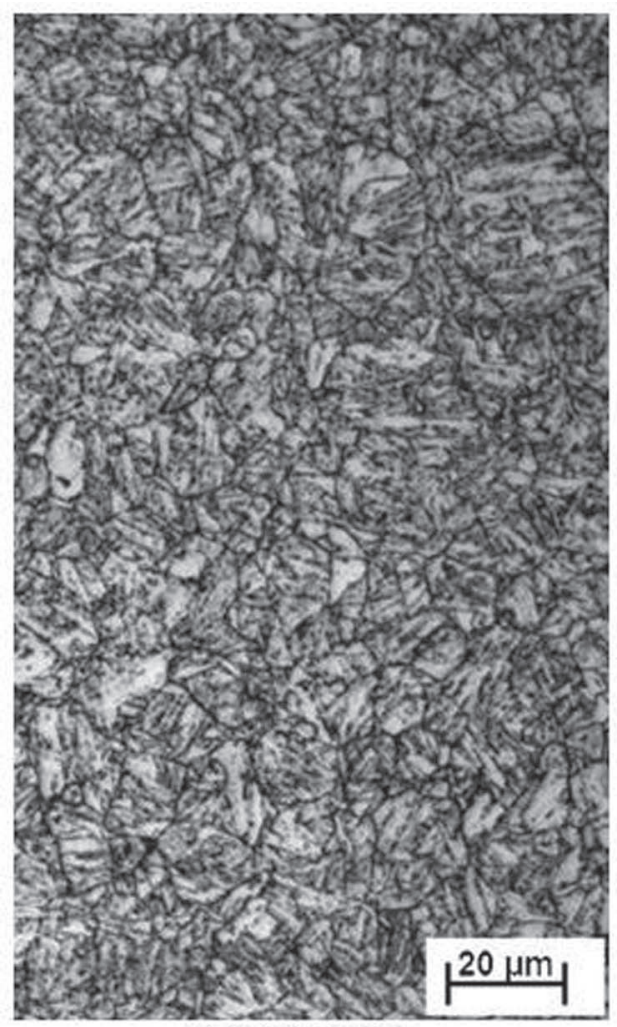

(a) Região I

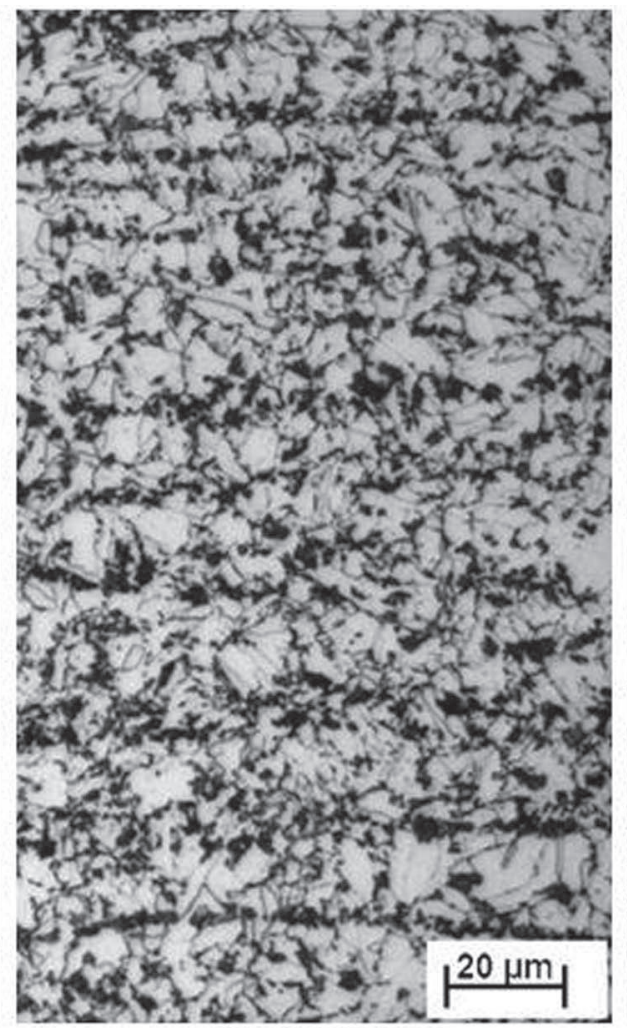

(b) Região II

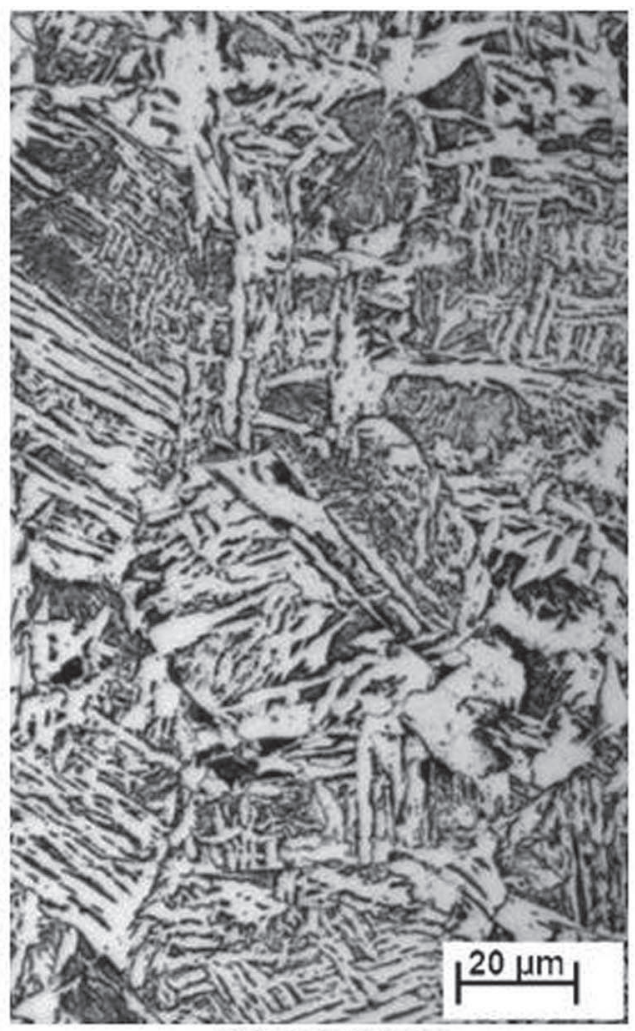

(c) Região III

Figura 6. Microestruturas das regiões I, II e III da ZTA do aço B, conforme indicado na Figura 4. Análise via microscopia ótica. Energia de soldagem: 1,6 kJ/mm. Aumento original: 500X. Ataque: nital $4 \%$.

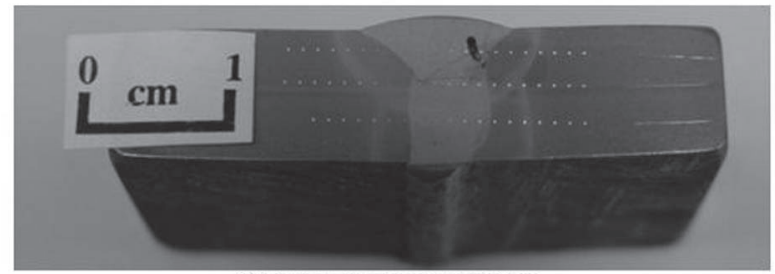

(a) Aspecto macrográfico.

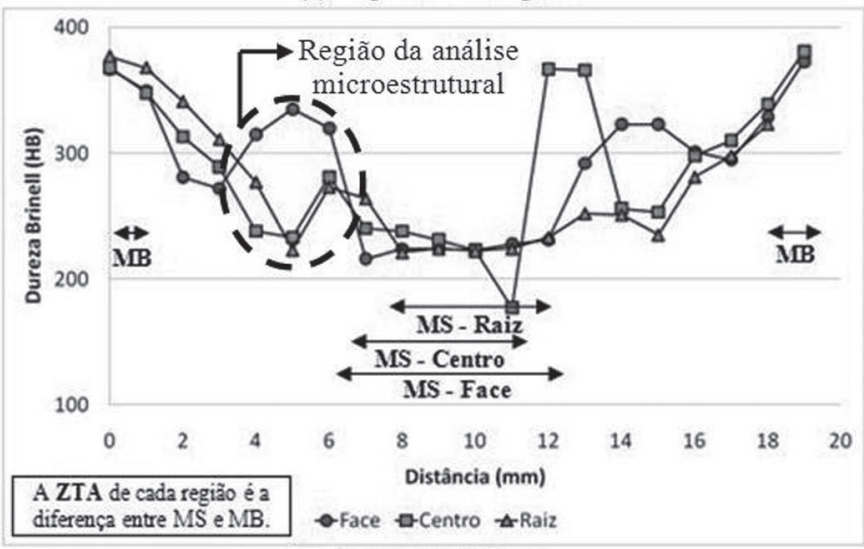

(b) Perfil de dureza.

Figura 7. Aspecto macrográfico e perfil de dureza Vickers da junta soldada do aço A com energia de soldagem de $1,0 \mathrm{~kJ} / \mathrm{mm}$.

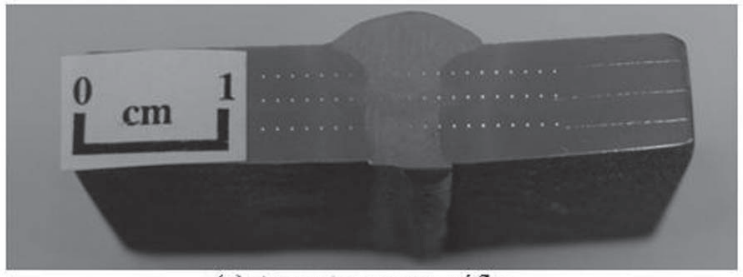

(a) Aspecto macrográfico.

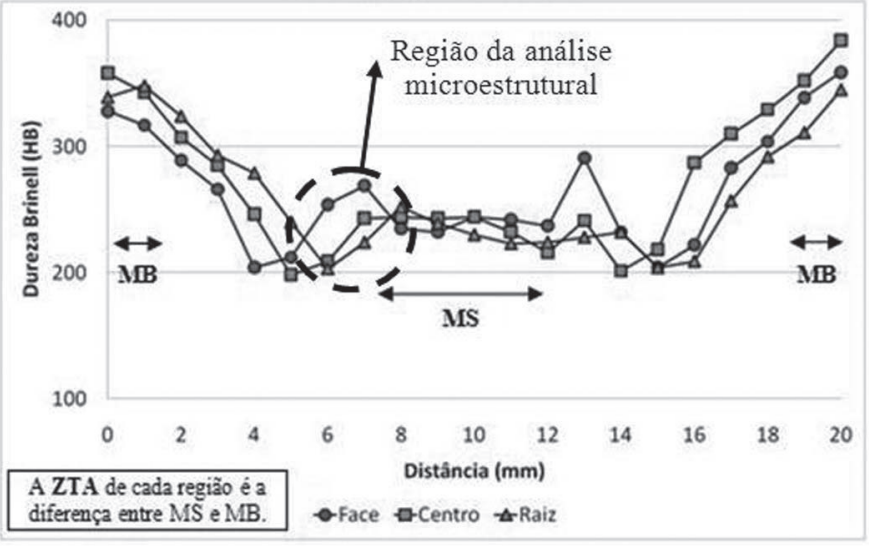

(b) Perfil de dureza.

Figura 8. Aspecto macrográfico e perfil de dureza Vickers da junta soldada do aço B com energia de soldagem de $1,0 \mathrm{~kJ} / \mathrm{mm}$. 


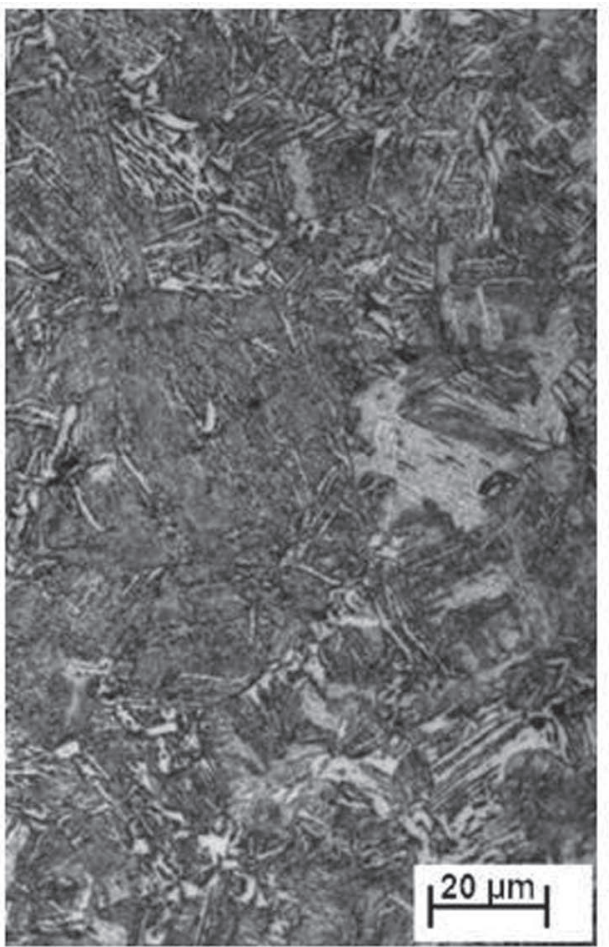

(a) ZTA - Face

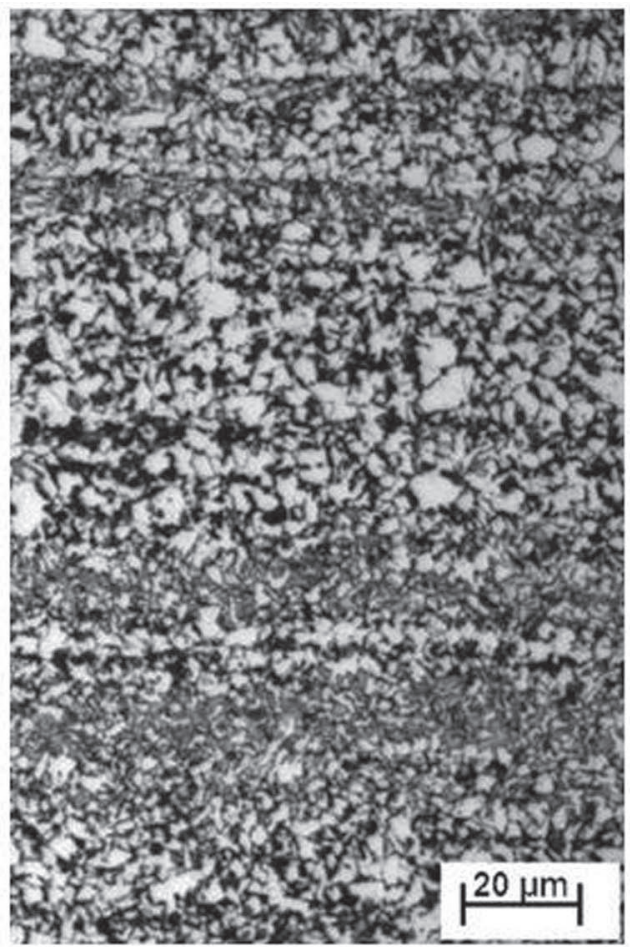

(b) ZTA - Centro

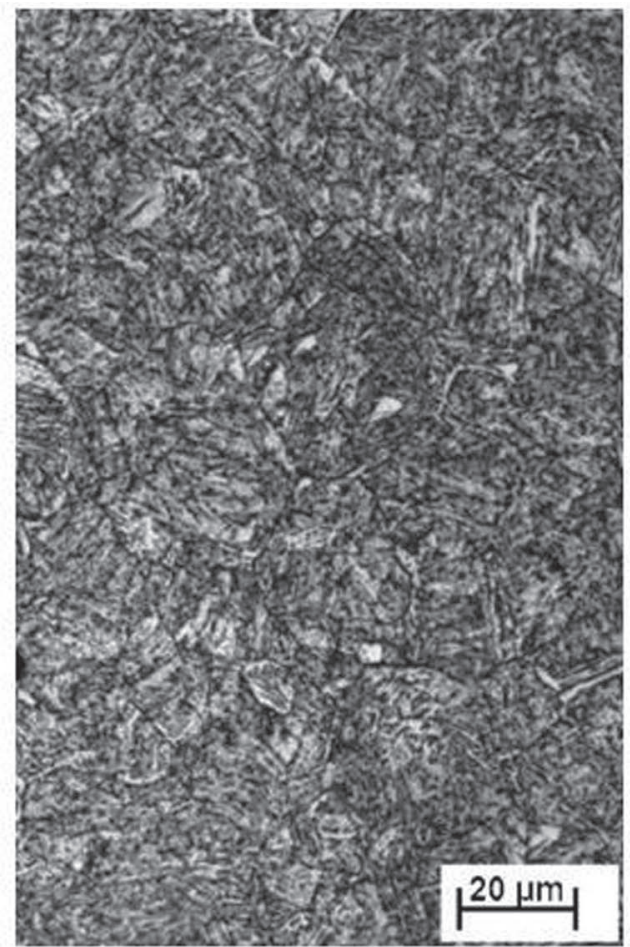

(c) ZTA - Raiz

Figura 9. Microestruturas de diferentes regiões da ZTA da junta soldada do aço A, conforme indicado no círculo tracejado na Figura 7. Análise via microscopia ótica. Energia de soldagem: 1,0 kJ/mm. Aumento original: 500X. Ataque: nital 4\%.

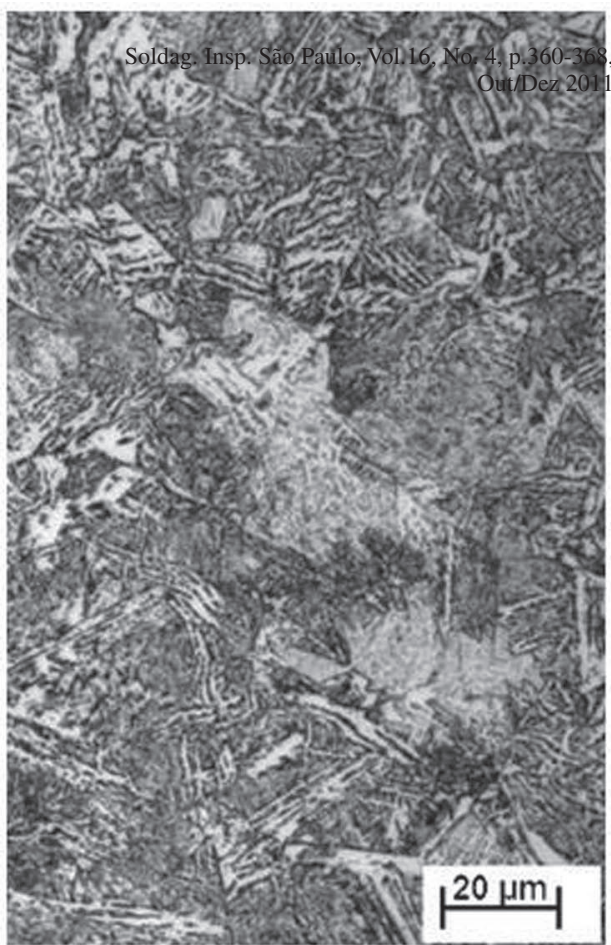

(a) ZTA - Face

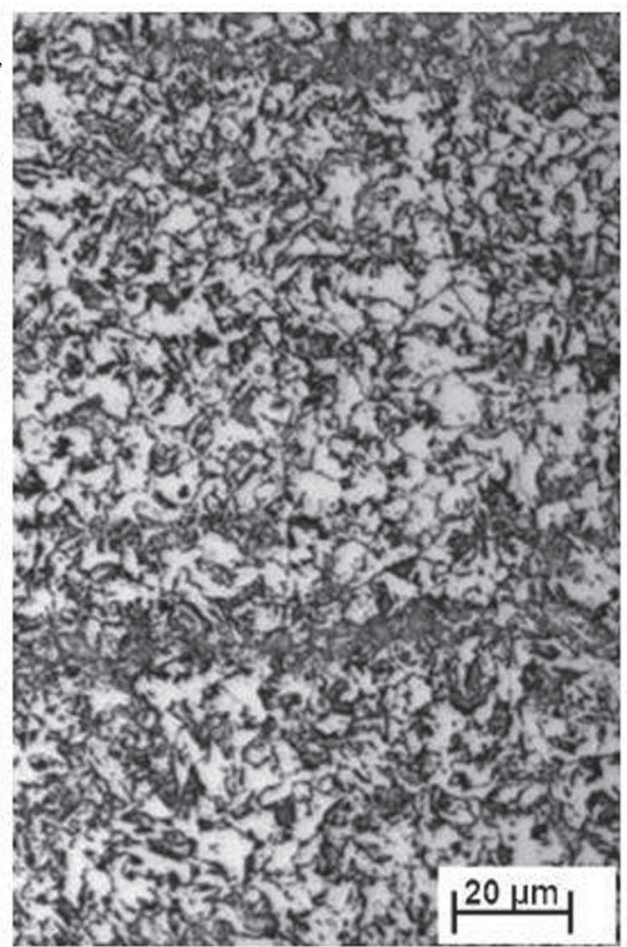

(b) ZTA - Centro

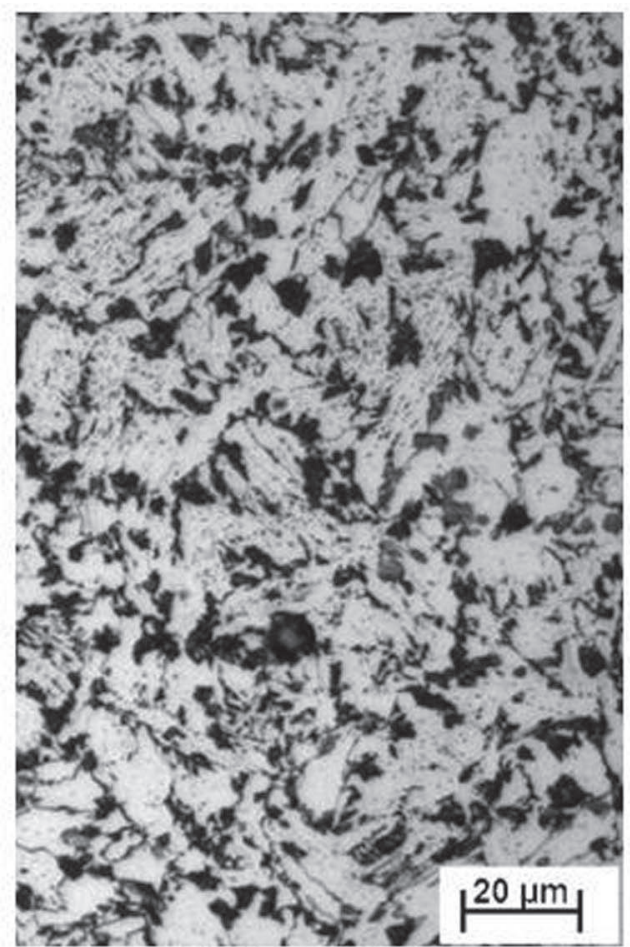

(c) ZTA - Raiz

Figura 10. Microestruturas de diferentes regiões da ZTA da junta soldada do aço B, conforme indicado no círculo tracejado na Figura 8. Análise via microscopia ótica. Energia de soldagem: 1,0 kJ/mm. Aumento original: 500X. Ataque: nital 4\%. 
As microestruturas relativas à ZTA nas regiões da face, do centro e da raiz, observadas na região indicada pelo círculo tracejado nas Figuras 7 e 8, são apresentadas nas Figuras 9 e 10, para os aços A e B, respectivamente. Observa-se que a microestrutura da ZTA na região da face da junta soldada do aço A é similar a do aço B, Figuras 9 (a) e 10 (a), diferindose na proporção dos constituintes (ferrita e martensita). Notase, também, que ambos os aços apresentam microestruturas diferentes na ZTA em regiões do centro e da raiz da junta soldada, Figuras 9 (b), 9 (c), 10 (b) e 10 (c). A explicação para este fato se baseia no efeito do segundo passe de solda sobre a microestrutura gerada pelo passe prévio [7].

As temperaturas de pico alcançadas nas regiões do centro e da raiz da junta soldada não proporcionam o crescimento do grão austenítico, causando seu refinamento e a formação de constituintes de menor dureza [7], tais como ferrita, perlita e bainita, e/ou promovendo a decomposição da martensita do metal base. Estes constituintes, em conjunto ou isolados, foram observados nas microestruturas das ZTA no centro e na raiz das juntas soldadas dos aços A, Figuras 9 (b) e 9 (c), e B, Figuras 10 (b) e 10 (c).

\subsection{Ensaios Mecânicos}

Na Tabela 3 são apresentados os resultados obtidos dos ensaios de dobramento das juntas soldadas. De maneira geral, percebese que o aço B apresenta melhores resultados de dobramento a $3 \mathrm{E}-90^{\circ}$ que o aço $\mathrm{A}$, principalmente quando utilizada a energia de soldagem de $1,6 \mathrm{~kJ} / \mathrm{mm}$. Este comportamento ocorreu, provavelmente, em decorrência do menor $\mathrm{CE}$ do aço $\mathrm{B}$, que proporcionou a formação de microestruturas mais dúcteis na sua ZTA, Figuras 6 (b), 6 (c) e 10. Estas microestruturas provavelmente conferiram melhor acomodação da deformação durante os ensaios de dobramento. Ressalta-se que, para a energia de soldagem de $1,6 \mathrm{~kJ} / \mathrm{cm}$, a maioria dos corpos de prova do aço B também foi aprovada a $180^{\circ}$.

Tabela 3. Resultados obtidos no ensaio de dobramento das juntas soldadas dos aços A e B, soldadas com aportes de calor de 1,0 e $1,6 \mathrm{~kJ} / \mathrm{mm}$.

\begin{tabular}{|c|c|c|c|c|c|}
\hline \multirow{3}{*}{ Aço } & \multirow{3}{*}{ Aporte de calor $(\mathrm{kJ} / \mathrm{mm})$} & \multirow{3}{*}{ Tipo de dobramento } & \multirow{3}{*}{ Número do ensaio } & \multirow{2}{*}{\multicolumn{2}{|c|}{$\begin{array}{c}\text { Dobramento } \\
3 \mathrm{E} \\
\end{array}$}} \\
\hline & & & & & \\
\hline & & & & $90^{\circ}$ & $180^{\circ}$ \\
\hline \multirow{12}{*}{$\mathbf{A}$} & \multirow{6}{*}{1,0} & \multirow{3}{*}{ Face } & 1 & Reprovado & - \\
\hline & & & 2 & Reprovado & - \\
\hline & & & 3 & Reprovado & - \\
\hline & & \multirow{3}{*}{ Raiz } & 1 & Reprovado & - \\
\hline & & & 2 & Reprovado & - \\
\hline & & & 3 & Reprovado & - \\
\hline & \multirow{6}{*}{1,6} & \multirow{3}{*}{ Face } & 1 & Reprovado & - \\
\hline & & & 2 & Reprovado & - \\
\hline & & & 3 & Reprovado & - \\
\hline & & \multirow{3}{*}{ Raiz } & 1 & Reprovado & - \\
\hline & & & 2 & Reprovado & - \\
\hline & & & 3 & Reprovado & - \\
\hline \multirow{12}{*}{ B } & \multirow{6}{*}{1,0} & \multirow{3}{*}{ Face } & 1 & Aprovado & Reprovado \\
\hline & & & 2 & Aprovado & Reprovado \\
\hline & & & 3 & Reprovado & - \\
\hline & & \multirow{3}{*}{ Raiz } & 1 & Reprovado & - \\
\hline & & & 2 & Reprovado & - \\
\hline & & & 3 & Aprovado & Reprovado \\
\hline & \multirow{6}{*}{1,6} & \multirow{3}{*}{ Face } & 1 & Aprovado & Aprovado \\
\hline & & & 2 & Aprovado & Aprovado \\
\hline & & & 3 & Aprovado & Aprovado \\
\hline & & \multirow{3}{*}{ Raiz } & 1 & Aprovado & Aprovado \\
\hline & & & 2 & Aprovado & Aprovado \\
\hline & & & 3 & Reprovado & - \\
\hline
\end{tabular}


Nas Figuras 11 e 12, apresentam-se os valores de energia absorvida das juntas soldadas dos aços A e B após ensaio de impacto Charpy-V.

Percebe-se que para a energia de soldagem de $1,6 \mathrm{~kJ} / \mathrm{mm}$, Figura 11, as juntas soldadas do aço B apresentam valores de energia absorvida superiores aos das juntas soldadas do aço A. Observa-se que, para as juntas soldadas do aço B, os valores de energia absorvida se elevam à medida que se afasta da linha de fusão (LF). Para a energia de soldagem de 1,0 kJ/mm, Figura 12, nota-se que as juntas soldadas do aço B apresentam valores de energia absorvida superiores aos das juntas soldadas do aço A, à exceção dos corpos de prova com entalhe a $2 \mathrm{~mm}$ da linha de fusão (LF $+2 \mathrm{~mm})$.

Os maiores valores de energia absorvida após ensaio de impacto Charpy-V para a junta soldada do aço B devem estar relacionados à presença de microestruturas mais tenazes nas regiões avaliadas ( $\mathrm{LF}, \mathrm{LF}+2 \mathrm{~mm}$ e $\mathrm{LF}+5 \mathrm{~mm}$ ), propiciadas pelo seu menor CE. A exceção observada para os corpos de prova com entalhe a $2 \mathrm{~mm}$ da linha de fusão das juntas soldadas com energia de soldagem de $1,0 \mathrm{~kJ} / \mathrm{mm}$ pode estar associada à espessura do aço B. Como a sua espessura é menor que a do aço A, a dissipação do calor gerado durante a soldagem ocorre mais lentamente, propiciando um maior crescimento de grão austenítico e a formação de microestruturas mais grosseiras próxima à linha de fusão. Como microestruturas mais grosseiras são deletérias à tenacidade [7], o aço B apresentou menor valor de energia absorvida a $2 \mathrm{~mm}$ da linha de fusão.

As juntas soldadas com baixa energia de soldagem $(1,0 \mathrm{~kJ} /$ $\mathrm{mm})$ apresentaram maiores valores de energia absorvida do que as soldadas com alto aporte $(1,6 \mathrm{~kJ} / \mathrm{mm})$, possivelmente devido ao refino da microestrutura causado pelo reaquecimento da ZTA do passe prévio, em decorrência do segundo passe de solda [7].

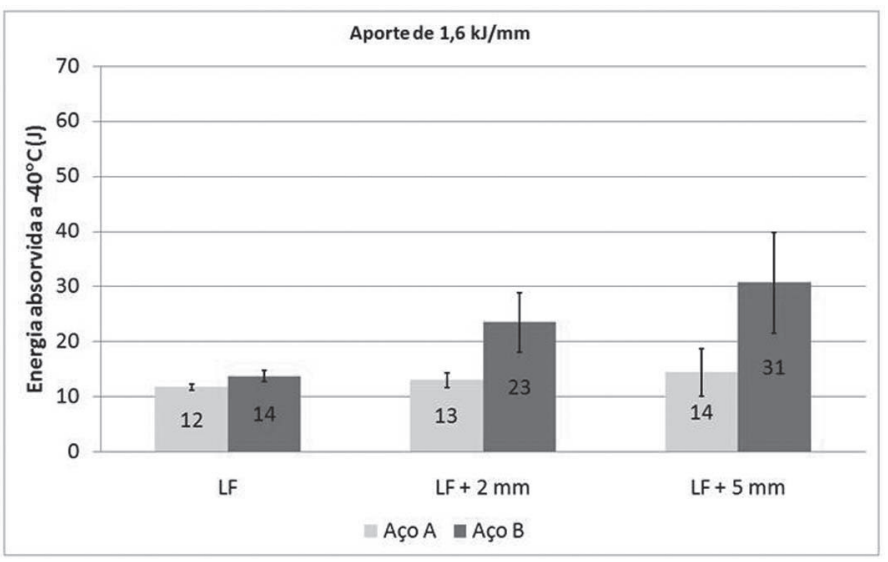

Figura 11. Resultados de energia absorvida das juntas soldadas dos aços A e B com energia de soldagem de $1,6 \mathrm{~kJ} / \mathrm{mm}$, em diferentes posições de entalhe, após ensaio de impacto Charpy-V a $40^{\circ} \mathrm{C}$.

Os menores valores de energia absorvida das juntas soldadas de ambos os aços foram observados para os corpos de prova em que o entalhe encontrava-se na linha de fusão. Este fato pode estar associado às microestruturas mais grosseiras e de menores temperaturas de transformação formadas nesta região, que são deletérias à tenacidade das juntas soldadas [7]. Na Figura 5 (c), que representa uma região da ZTA da junta soldada do aço A próxima à linha de fusão, nota-se que a microestrutura presente é mais grosseira que a observada na Figura 5 (b), uma região da ZTA mais afastada da linha de fusão. Isto também foi observado para o aço B, Figuras 6 (b) e 6 (c).

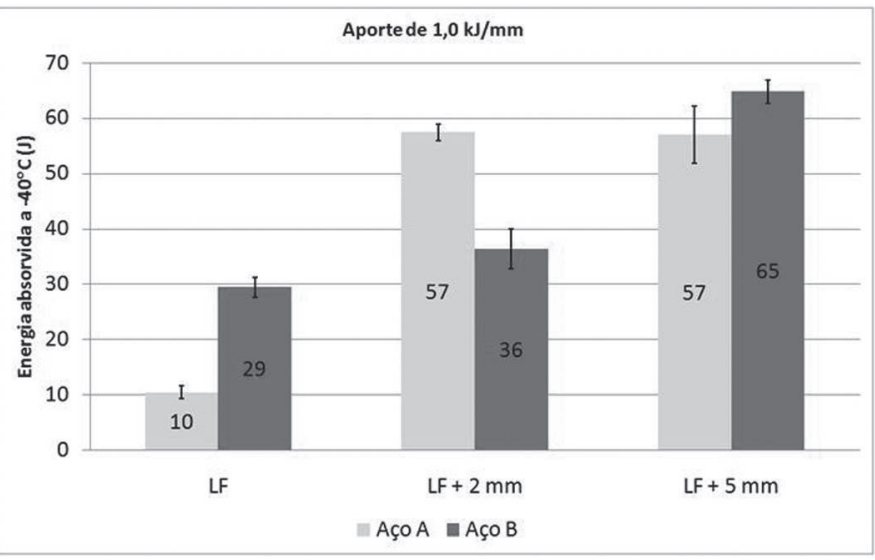

Figura 12. Resultados de energia absorvida das juntas soldadas dos aços A e B com energia de soldagem de 1,0 kJ/mm, em diferentes posições de entalhe, após ensaio de impacto Charpy-V a $40^{\circ} \mathrm{C}$.

\section{Conclusões}

Para as espessuras avaliadas $(9,5 \mathrm{~mm}$ para o aço A e $8,0 \mathrm{~mm}$ para o aço B), concluiu-se que nenhum dos aços necessita de pré-aquecimento para soldagem, por não terem apresentado trincamento a frio induzido por hidrogênio à temperatura ambiente.

De maneira geral, o aço A apresentou os maiores valores de dureza na ZTA que o aço B, independente da energia de soldagem utilizada.

Percebeu-se que o aço B apresentou melhores resultados de dobramento a $3 \mathrm{E}-90^{\circ}$, atendendo, inclusive, a especificação do metal base. Este aço apresentou, também, maiores valores de energia absorvida.

Desta forma, concluiu-se que o aço B apresentou melhor soldabilidade que o aço A, muito em função de seu menor CE.

\section{Referências Bibliográficas}

[1] NEWELL, W. F. Understanding and Using Carbon Equivalent Formulas. WELDING JOURNAL. Setembro/1995, p. 57-58.

[2] SUZUKI, H. Comparison of Carbon Equivalents for Steel Weldability. RIVISTA ITALIANA DELLA SOLDATURA. Ano 39, n. 4, julho-agosto/1987, p. 339-349.

[3] DEFOURNY, J. Guide to Weldability and Metallurgy of Welding of Steels Processed by Thermomechanical Rolling or by Accelerated Cooling. WELDING IN THE WORLD. Vol. 3, n. 1, 1994, p. 2-33.

[4] NORMA JIS Z 3158 - Method of Y Groove Cracking Method. JAPENESE INTERNATIONAL STANDARD, 1993, 6 . 
[5] CÓDIGO ASME, Seção IX - Qualificação de Soldagem. THE AMERICAN SOCIETY OF MECHANICAL ENGINEERS, 1980, 212p.

[6] NORMA ASTM-A370 - Standard Test Methods and Definitions for Mechanical Testing of Steel Products. AMERICAN SOCIETY FOR TESTING AND MATERIALS INTERNATIONAL, 2009, 47p.

[7] SILVA, R. F. Caracterização da Zona Termicamente Afetada de Aço Produzido via Resfriamento Acelerado: 2010, 194p. Dissertação (Mestrado) - Departamento de Engenharia Metalúrgica, Universidade Federal de Minas Gerais. 